Abstract FRI0361 - Table 1. frequency of APOs, pPROM and PE in the 134 analysed pregnancies

\begin{tabular}{|l|l|}
\cline { 2 - 2 } \multicolumn{1}{c|}{} & \multicolumn{1}{c|}{$\mathbf{N}(\%)$} \\
\hline N of live birth & $\mathbf{1 2 0 ( 9 0 \% )}$ \\
\hline N of APOs & $39(29 \%)$ \\
\hline Premature miscarriage $\left(<10^{\text {th }}\right.$ w) & $\mathbf{9 ( 7 \% )}$ \\
\hline Intrauterine fetal death $\left(>10^{\text {th }}\right.$ w) & $5(4 \%)$ \\
\hline with PE & $1(20 \%)$ \\
\hline Perinatal death $\left(<30^{\text {th }}\right.$ day of life) & $\mathbf{1 ( 1 \% )}$ \\
\hline with PE & $1(100 \%)$ \\
\hline All preterm birth $\left(<37^{\text {th }}\right.$ w) & $\mathbf{2 4 ( 1 8 \% )}$ \\
\hline Preterm birth $\left(<34^{\text {th }}\right.$ w) & $\mathbf{3 ( 2 \% )}$ \\
\hline with $p P R O M$ & $2(67 \%)$ \\
\hline Preterm birth $\left(34^{\text {th }}-36^{\text {th }}\right.$ w) & $\mathbf{2 1 ( 1 6 \% )}$ \\
\hline with $p P R O M$ & $7(33 \%)$ \\
\hline with PE & $2(10 \%)$ \\
\hline
\end{tabular}

Abstract FRI0361 - Table 2. frequency of preterm birth and pPROM among the 120 live birth, according to exposure (or not) to corticosteroids $>35 \mathrm{mg} /$ week during the three trimesters

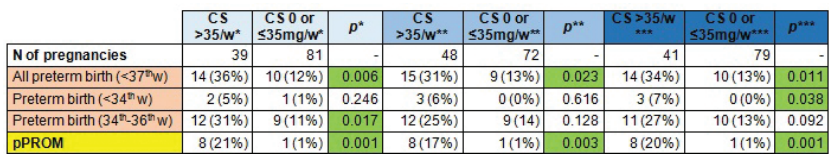

* 1 st trimester; ** 2nd trimester; *** 3 rd trimester

Conclusions: Use of IS seems to be associated with premature miscarriages; this could reflect their use in patients with a more severe disease phenotype. The exposure to CS in doses greater than $35 \mathrm{mg} / \mathrm{w}$ in the $1 \mathrm{st}$ trimester seems to be associated with preterm birth at 34th-36th w, while in the 3rd trimester with severe preterm birth $(<34$ th $w)$, that could be related to the strong association observed between CS use and pPROM.

Disclosure of Interest: None declared

DOI: 10.1136/annrheumdis-2018-eular.5085

\section{FRI0362 PREVALENCE, RISK FACTORS, AND IMPACT ON MORTALITY OF NEUROPSYCHIATRIC LUPUS: A LARGE PROSPECTIVE SINGLE-CENTRE STUDY}

G.Y. Ahn ${ }^{1}$, D. Kim ${ }^{1}$, S. Won ${ }^{2}$, S.T. Song ${ }^{1}$, H.-J. Jeong ${ }^{1}$, I.W. Sohn ${ }^{1}$, S. Lee ${ }^{1}$, Y B. Joo ${ }^{3}$, S.-C. Bae ${ }^{1}{ }^{1}$ Hanyang University Hospital for Rheumatic Diseases; ${ }^{2}$ Clinical Research Center for Rheumatoid Arthritis (CRCRA), Seoul; ${ }^{3}$ St. Vincent's Hospital, The Catholic University of Korea, Suwon, Korea, Republic Of

Background: Neuropsychiatric involvement is one of the most serious involvement of SLE and generally associated with a worse prognosis. However, previous reports about the prevalence and risk factors of neuropsychiatric systemic lupuc erythematosus (NPSLE) have yielded inconsistent findings. Also, there are only few studies of the prognosis of NPSLE, especially in a large prospective cohort. Objectives: To identify the prevalence, risk profiles, and impact on mortality of NPSLE.

Methods: Patients from the Hanyang BAE lupus cohort were registered and followed from 1998 to 2015. Demographics, autoantibodies, SLEDAI-2K and SLICC/ACR damage index were collected at baseline and then annually. Patients registered within 12 months of SLE development were grouped as the inception cohort and analysed separately to elucidate the clinical features at disease onset. NP manifestations were defined using the ACR 19 case definitions and Ainiala NPSLE that did not include minor NP events ${ }^{1}$. Mortality data were derived by linking data from the Korean National Statistics Office.

Results: The prevalence of NPSLE by ACR 19 case definition was $38.3 \%$, and $19.3 \%$ by Ainiala criteria. Higher SLEDAI, APLA positivity, absence of anti-dsDNA antibody at SLE diagnosis and fewer years of education incresed NPSLE risk.
Patients with any NPSLE manifestation had a three-fold increased risk of mortality (HR 3.09, $p=0.04$ ), and patients with focal CNS NPSLE showed nearly an eightfold increased risk of mortality in SLE patients (HR=7.83, $p<0.01)$. Among the 216 patients with Ainiala NPSLE, sixty-four (29.6\%) had multiple events. The two most common symptom combinations were seizure with CVA (18 patients) and seizure with psychosis (8 patients).

Abstract FRI0362 - Table 1. Risk factors for the development of NPSLE in the inception cohort $(\mathrm{N}=388)$

\begin{tabular}{|c|c|c|c|c|c|}
\hline & $\begin{array}{l}\text { NPSLE } \\
(\mathrm{n}=88)\end{array}$ & $\begin{array}{l}\text { Non-NPSLE } \\
(n=300)\end{array}$ & $P$ & $\begin{array}{l}\text { Adjusted OR } \\
(95 \% \mathrm{Cl})\end{array}$ & $P$ \\
\hline \multicolumn{6}{|l|}{ Demographics } \\
\hline Age at SLE diagnosis & $\begin{array}{r}28.2 \\
\pm 11.6\end{array}$ & $29.3 \pm 11.3$ & 0.42 & $\begin{array}{c}0.99(0.97- \\
1.01)\end{array}$ & 0.45 \\
\hline Female sex & $\begin{array}{c}81 \\
(92.1)\end{array}$ & $270(90.0)$ & 0.71 & $\begin{array}{c}1.88(0.71- \\
4.96)\end{array}$ & 0.20 \\
\hline $\begin{array}{l}\text { SLEDAI at diagnosis, NP } \\
\text { manifestations excluded }^{\text {a }}\end{array}$ & $\begin{array}{l}4.7 \\
\pm 4.5\end{array}$ & $3.8 \pm 3.3$ & 0.10 & $\begin{array}{l}1.08(1.01- \\
1.16)\end{array}$ & $0.02^{*}$ \\
\hline $\begin{array}{l}\mathrm{SDI} \text { at diagnosis, NP } \\
\text { manifestations excluded }^{\mathrm{b}}\end{array}$ & $\begin{array}{c}0.2 \\
\pm 0.4\end{array}$ & $0.1 \pm 0.4$ & 0.43 & $\begin{array}{c}1.23(0.72- \\
2.11)\end{array}$ & 0.45 \\
\hline HTN & $5(5.8)$ & $16(5.4)$ & 1.00 & $\begin{array}{c}1.14(0.38- \\
3.37)\end{array}$ & 0.82 \\
\hline Education (years) & $\begin{array}{l}12.2 \\
\pm 3.1\end{array}$ & $13.0 \pm 3.3$ & $0.05^{*}$ & $\begin{array}{l}0.92(0.85- \\
1.00)\end{array}$ & $0.04^{*}$ \\
\hline Anti-dsDNA antibody positivity & $\begin{array}{c}61 \\
(69.3)\end{array}$ & $238(79.3)$ & 0.07 & $\begin{array}{c}0.43(0.24- \\
0.78)\end{array}$ & $<0.01^{*}$ \\
\hline APLA positivity & $\begin{array}{c}40 \\
(45.5)\end{array}$ & $96(32.0)$ & $0.03^{*}$ & $\begin{array}{c}1.72(1.03- \\
2.87)\end{array}$ & $0.04^{*}$ \\
\hline
\end{tabular}

*Values are number (percentage) or mean \pm standard deviation. a. SLEDAI was calculated using the remaining items except CVA, seizure, organic brain syndrome, psychosis, visual disturbance, cranial nerve disorder. b.SDI was calculated using the remaining items except CVA, myelopathy, seizure, psychosis, cognitive impairment, carinal neuropathy, and peripheral neuropathy.
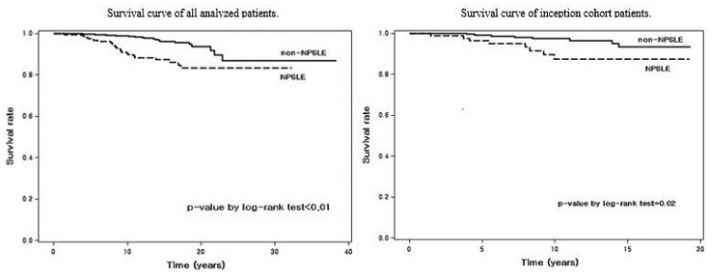

Abstract FRI0362 - Figure 1. Kaplan-Meier survival curves for NPSLE and non-NPSLE patients; Inception cohort and all analysed patients.

Conclusions: Higher SLEDAI, APLA positivity, absence of anti-dsDNA antibody at SLE diagnosis and fewer years of education are risk factors for development of NPSLE. Presence of NPSLE, especially focal CNS NPSLE, increased the risk of mortality in SLE patients.

\section{REFERENCE:}

[1] Ainiala $\mathrm{H}$, Hietaharju A, Loukkola $\mathrm{J}$, et al. Validity of the new American College of Rheumatology criteria for neuropsychiatric lupus syndromes: a population-based evaluation. Arthritis Rheum. 2001;45:419-423.

Disclosure of Interest: None declared

DOI: 10.1136/annrheumdis-2018-eular.4058

\section{FRI0363 POSITIVE REMODELLING INDEX AND LOW ATTENUATION NON-CALCIFIED CORONARY PLAQUES: MARKERS OF VULNERABLE CORONARY PLAQUES IN SYSTEMIC LUPUS?}

G. Stojan ${ }^{1}$, L. Magder ${ }^{2}$, M. Petri ${ }^{1} .{ }^{1}$ Rheumatology, Johns Hopkins University; ${ }^{2}$ Epidemiology, University of Maryland, Baltimore, USA

Background: Accelerated atherosclerosis leading to premature coronary artery disease remains the major cause of late death in SLE. Coronary plaques with large necrotic/lipid core and/or a thin fibrous cap are prone to rupture, leading to acute coronary events. In coronary CT angiography, plaque lipid content correlates with lower CT attenuation values when compared with fibrotic tissue 